\title{
PPG em Letras: uma trajetória inovadora na PUCRS
}

\author{
PPG in Letters: an innovative trajectory in PUCRS
}

\author{
Jorge Luis Nicolas Audy \\ Pontifícia Universidade Católica do Rio Grande do Sul - Porto Alegre - Rio Grande do Sul - Brasil \\ Pró-Reitor de Pesquisa, Inovação e Desenvolvimento \\ Clarissa Lopes Bellarmino \\ Pontifícia Universidade Católica do Rio Grande do Sul - Porto Alegre - Rio Grande do Sul - Brasil \\ Coordenadora de Estruturas de Pesquisa
}

\begin{abstract}
Resumo: O artigo trata da trajetória histórica do Programa de Pós-Graduação Stricto Sensu em Letras, da Faculdade de Letras da PUCRS, desde a sua criação em 1969 até os dias atuais, contemplando alguns aspectos acadêmico-administrativos e ações, realizados em prol da sua consolidação e da excelência no ensino, na pesquisa e na extensão, que o tornaram referência nacional e internacional na área.
\end{abstract}

Palavras-chave: Trajetória; Pós-graduação; Letras; Consolidação e excelência

\begin{abstract}
The article deals with the historical trajectory of the Post-Graduate Programme in Letters, within the Letters Faculty of PUCRS, since its opening in 1969 to current days. The article contemplates some academic-administrative aspects and actions, carried out for the sake of the consolidation and excellence in teaching research, and extension that has become a national and international reference in its area.
\end{abstract}

Keywords: Trajectory; Post-graduation; Letters; Consolidation and excellence

\section{O surgimento}

A PUCRS iniciou suas atividades como IES no ano de 1931, ainda no Colégio Marista Rosário, com foco na formação de profissionais nas áreas de ciências políticas e econômicas, ampliando com o tempo para diversas outras áreas do conhecimento. Em 1948 a Instituição se tornou Universidade e em 1951 recebeu o título de Pontifícia. Nas suas primeiras décadas, a Instituição atuou na primeira missão da Universidade: o ensino e a formação dos estudantes. Somente em meados da década de 1960, quando se instalou na Avenida Ipiranga, a jovem Universidade iniciou suas atividades mais sistemáticas de pesquisa, com a criação de dois Programas de PósGraduação Stricto Sensu, sendo um deles o Mestrado em Linguística e Letras, do então Instituto de Letras e Artes (ILA), cujo Diretor era o Ir. Liberato, sucedido em 1974 pelo Ir. Mainar Longhi. O outro foi o Mestrado em Cirurgia e Traumatologia Bucomaxilofacial.

Em 1969 a PUCRS iniciou sua trajetória de formação de mestres e doutores, incorporando em sua missão a dimensão da pesquisa, que a diferencia e a qualifica como uma Universidade de Excelência no cenário nacional. Entre as décadas de 1970 e 1980, a PUCRS começou a definir suas vocações e criaram-se as condições para a construção de uma das mais importantes e reconhecidas Universidades brasileiras de pesquisa.

O primeiro coordenador da Pós-Graduação na PUCRS foi o Irmão Elvo Clemente (Antônio João Silvestre Mottin) que ficou na coordenação até o ano de 1976, quando assumiu a Superintendência de Pesquisa e Pós-Graduação, órgão administrativo que estruturou inicialmente a Pós-Graduação na PUCRS, sendo alterada a nomenclatura, posteriormente, para Pró-Reitoria de Pesquisa e Pós-Graduação, em 1983. Na década de 1980, o Ir. Elvo acumulou o cargo de Pró-Reitor de Pesquisa e Pós-Graduação e Pró-Reitor de Extensão Universitária. No ano de 1988, com a reestruturação administrativa, assumiu a nova Pró-Reitoria de Extensão o Prof. Dr. Urbano Zilles, até então Diretor do Instituto de Filosofia e Ciências Humanas, que tomou posse como Pró-Reitor na nova Pró-Reitoria de Pesquisa e Pós-Graduação. 
A trajetória inovadora do Programa de Pós-Graduação em Letras (PPGL), na década de 1960, quebrou barreiras e foi referência para o restante da Universidade, que conta hoje com 23 Programas de Pós-Graduação Acadêmicos, sendo que 11 deles em nível de excelência internacional (conceitos 6 e 7 da CAPES) e 06 em nível de excelência nacional (conceito 5 da CAPES), sendo umas das 5 melhores Universidades (entre públicas, comunitárias e privadas), considerando a média de avaliação da Trienal 2010-2012 da CAPES, e a primeira comunitária e privada no país dentre as Instituições com mais de 10 Programas de Pós-Graduação.

\section{A trajetória}

O Programa de Pós-Graduação em Letras (PPGL) foi criado em 1969, pelo Conselho Universitário da PUCRS, sob a denominação de Curso de Pós-Graduação em Letras. Em 1970, ano de sua instalação oficial e início de suas atividades, passou a chamar-se de Curso de Pós-Graduação em Linguística e Letras (CPGLL) implantando, assim, o Programa de Mestrado em Linguística Aplicada (atual Linguística), e em 1972, o Mestrado em Teoria Literária (atual Teoria da Literatura), no Instituto de Letras e Artes (ILA), hoje Faculdade de Letras (FALE). O Mestrado foi credenciado, em 1973, pelo extinto Conselho Federal de Educação. A criação do nível de Doutorado, nas áreas de Linguística Aplicada e Teoria da Literatura, foi aprovada pelo Conselho Universitário da PUCRS em 1977, iniciando suas atividades em 1978. O Curso, então, em nível de Mestrado e de Doutorado, foi credenciado pelo extinto Conselho Federal de Educação em 5 de dezembro de 1985, através do Parecer 864/85, e recredenciado em 7 de outubro de 1993, pelo Parecer 639/93.

No seu primeiro ano de funcionamento em 1970, o quadro de docentes era composto pelos professores Ir. Elvo Clemente (Antônio João Silvestre Mottin), Dr. Wilson Chrysostomo Guarany, Dra. Leonor Scliar Cabral e Dra. Leda Bisol, e dos visitantes Dr. Paulino Vandresen (UFSC), Dr. Landon Lockett (University of Austin/Texas/ USA), Dra. Petrona Dominguez Rodriguez-Pasqués (Georgetown University/USA).

O Programa de Pós-Graduação em Letras, desde a criação do Doutorado até 2004, intensificou suas atividades de formação e de pesquisa em nível regional, nacional e internacional, voltando-se inicialmente para a cultura sul-rio-grandense e acolhendo alunos de outras Instituições de Ensino Superior do Rio Grande do Sul da capital e do interior e, posteriormente, recebendo alunos de todas as regiões brasileiras e do exterior. Empreendeu algumas ações de cunho acadêmico-administrativo como a contratação de professores estrangeiros, a realização de parcerias mediante acordos, intercâmbios e convênios, a ampliação de suas áreas de concentração, a integração no sistema de bolsas das agências de fomento e divulgação de sua produção intelectual.

Importante meio de divulgação da produção intelectual deste período e até os dias atuais tem sido a revista Letras de Hoje, criada em 1967, e que se vincula ao PPGL.

No tocante à sua estrutura, as duas áreas de concentração - Linguística e Teoria da Literatura permitiram abranger de forma mais ampla e intensa a produção intelectual e artística com resultados muito expressivos nesta fase. Dessa forma, a área de Linguística voltou-se para Psicolinguística, Sociolinguística e Teoria da Variação, Texto e Discurso, Lógica da Linguagem Natural, Fonologia, Sintaxe e Semântica. A área de Teoria da Literatura optou pela avaliação crítica da produção e recepção literárias, pela recuperação e historicização da memória literária, pelo sistema literário de língua portuguesa e de outras línguas, pelas teorias da leitura e formação do leitor infantil e juvenil.

$\mathrm{Na}$ década de oitenta, visando à formação de novos autores e o desenvolvimento da criação literária, o escritor e professor Luiz Antonio de Assis Brasil implementou a Oficina de Criação Literária, pelas quais passaram alguns escritores contemporâneos tais como: Cíntia Moscovich, Letícia Wierzchowski, Michel Laub, Daniel Galera, Amilcar Bettega Barbosa, Daniel Pelizzari, Clarah Averbuck, Bernardo Moraes e Robertson Frizero.

No período entre 1989 e 2009, o PPGL realizou muitos eventos nacionais e internacionais nas áreas de Linguística e de Literatura, seus docentes passaram a participar mais de eventos de referência e ampliar o intercâmbio com outras instituições, as relações com as associações científicas, as oportunidades de divulgação dos resultados de pesquisa e as representações em comissões científicas nas esferas privada e pública.

O corpo docente qualificado passou a se projetar ainda mais com a concessão de bolsa de Produtividade do CNPq, destinada a pesquisadores que se destacam na área e na produção científica. Dessa forma, podem-se citar os professores que, no período entre 2000 e 2004, participaram do programa de bolsas: Alice Therezinha Campos Moreira, Antonio João Silvestre Mottin (Ir. Elvo Clemente), Leci Borges Barbisan, Leda Bisol, Luiz Antonio de Assis Brasil e Silva, Maria da Gloria Bordini, Maria Eunice Moreira, Maria Luiza Ritzel Remedios, Regina Ritter Lamprecht, Regina Zilberman, Solange Medina Ketzer e Vera Teixeira de Aguiar.

Desde 1969 até o ano de 2004, o PPGL teve como coordenadores os professores: Ir. Dr. Elvo Clemente (Antônio João Silvestre Mottin), que exerceu essa função no período de 1969 até 1976; Dr. José Marcelino Poersch, exerceu a coordenação entre 1976 e 1984; de 1972 a 
1975, o Dr. Wilson C. Guarany desempenhou a função de coordenador pedagógico do Curso; e de 1984 a 2004, a coordenação foi exercida pela Dra. Regina Zilberman.

Ao longo desse período, o Programa de PósGraduação em Letras foi avaliado, inicialmente, com o conceito $\mathrm{B}+\mathrm{e}$ conceito $\mathrm{A}$, quando a CAPES avaliava atribuindo conceitos (A, B, C, D e E), sendo o A o de maior importância. A CAPES passou a atribuir nota a partir de 1998, assim o PPGL recebeu a nota 5 nas avaliações de 1998-2000 e 2001-2003.

\section{A atualidade}

Acompanhando a trajetória dos últimos dez anos, compreendidos desde a posse do Reitor Joaquim Clotet em 2005 até o ano de 2015, e sob uma nova visão de universidade, o PPGL reestruturou-se para enfrentar os novos desafios da sua área, estabelecidos através da CAPES, e do Plano Estratégico da PUCRS, no âmbito do ensino, da pesquisa, da extensão, da qualidade, da relevância e da internacionalização.

No âmbito do ensino, o PPGL acenou para um novo viés na área de Literatura e possibilitou estudos e defesas de tese e dissertação em escrita literária, estimulando o trabalho criativo através de oficinas. Nessa perspectiva, e sob forte demanda, propôs a criação da área de Escrita Criativa em 2011, inédita no Brasil, possibilitando a produção de dissertações e teses voltadas à criação literária, bem como ao desenvolvimento de trabalhos na forma de documentários, biografias intelectuais de escritores, produção de roteiros teatrais e fílmicos, roteiros de websérie e narrativas híbridas, acompanhados de discussão teórica sobre o processo de criação. Os acervos literários e documentais, localizados no DELFOS - Espaço de Documentação e Memória Cultural -, ficam à disposição dos discentes e docentes para investigação e aulas in loco sobre o processo criativo dos escritores, através do manuseio e da análise dos manuscritos, correspondências, fotografias e anotações registradas em livros e outros materiais.

No campo da pesquisa, as ações voltam-se para a articulação entre as áreas do PPGL, de modo a oferecer um lócus comum sustentado pela linha de pesquisa Fundamentos Linguístico-Literários da Linguagem - que associa Linguística e Literatura ao estudo de teorias do campo abrangente da linguagem.

A partir da política institucional de padronização das Estruturas de Pesquisa, os pesquisadores do PPGL e alunos, atualmente, estão inseridos em alguns dos 3 Centros de Pesquisa (Centro de Estudos Linguísticos (CELING), Centro de Estudos Literários (CELIT) e Centro de Referência para o Desenvolvimento da Linguagem (CELIN)), dos 13 Núcleos de
Pesquisa e dos 28 Grupos de Pesquisa, certificados pelo CNPq.

Os professores do PPGL com bolsa de Produtividade em Pesquisa do CNPq, no período entre 2005 e 2015, que mantiveram ou progrediram nos níveis de classificação definidos pela agência, segundo critérios de relevância, originalidade e repercussão da produção científica, formação de recursos humanos, desenvolvimento de projetos de pesquisa, inserção internacional, impacto social das pesquisas entre outros, foram: Ana Maria Lisboa de Mello, Carlos Alexandre Baumgarten, Cláudia Regina Brescancini, Leci Borges Barbisan, Leda Bisol, Lilian Cristine Scherer, Luiz Antonio de Assis Brasil e Silva, Maria da Gloria Bordini, Maria Eunice Moreira, Maria Luiza Ritzel Remedios, Regina Ritter Lamprecht, Regina Zilberman, Sérgio de Moura Menuzzi, Sérgio Luiz Prado Bellei, Solange Medina Ketzer e Vera Teixeira de Aguiar. A docente Vera Wannmacher Pereira recebeu bolsa de Produtividade em Desenvolvimento Tecnológico e Extensão Inovadora - DT, que tem por finalidade distinguir o pesquisador por apresentar produção em desenvolvimento tecnológico e inovação.

Os esforços do PPGL pela busca da excelência acadêmico-científica comprovam-se pela produção científica de qualidade, divulgada em periódicos indexados e classificação Qualis e em eventos científicos, e pela qualificação docente e discente, estimulada para a participação em intercâmbios e missões, mediante cooperação com outras IES e pesquisadores, para a realização de Pós-Doutorado e doutorado sanduíche, para a coorientação e cotutela de teses, bem como participação em bancas de defesa, de seleção e de julgamento.

A consolidação do PPGL e o reconhecimento por sua excelente atuação e inserção de titulados docentes em outras IES, contribuiu e tem contribuído para a expansão da pós-graduação brasileira.

Os professores que exerceram o cargo de coordenadores do PPGL no período foram: Profa. Dra. Regina Ritter Lamprecht, de dezembro de 2004 a 14 de maio de 2008; Profa. Dra. Ana Maria Lisboa de Mello, de 15 de maio de 2008 a 7 de dezembro de 2012; Profa. Dra. Maria da Glória Corrêa di Fanti, de 8 de dezembro de 2012-atual.

Nas recentes avaliações da CAPES, o Programa de Pós-Graduação em Letras recebeu as notas 6 na avaliação do período de 2004-2006, nota 5 no período 2007-2009 e nota 6 no período 2010-2012, o que o coloca no rol dos cursos considerados de excelência internacional.

\section{A visão de futuro}

Este lindo caminho edificado pelo Programa de PósGraduação em Letras, tendo sido o primeiro PG em Letras 
do RS e da região sul do país, é resultado de um grupo de pessoas, pesquisadores competentes e dedicados, que, ao longo de 46 anos desenvolvem um trabalho sério e reconhecido, que orgulham nossa Universidade. Hoje, as Profas. Regina Kohlrausch (Diretora da FALE) e a Profa. Maria da Gloria Corrêa di Fanti (Coordenadora do PPG em Letras) têm a responsabilidade de liderar o qualificado grupo de pesquisadores (estudantes e docentes) e técnicos administrativos que, em breve, farão parte da nova Escola de Comunicação e Letras da PUCRS.

Ao longo de sua trajetória na pesquisa, o PPG em Letras abriu novas portas, identificou oportunidades, inovou e mostrou o caminho que muitas outras áreas $\mathrm{e}$ PPGs da Universidade trilharam nos anos seguintes, a partir de 1969. Formou toda uma geração de pesquisadores e docentes que atuam em algumas das mais importantes Universidades e Instituições de Educação Superior do RS e do Brasil. Muitos pesquisadores egressos dos cursos de mestrado e doutorado tiveram e têm relevante papel nas instâncias científicas de nosso país, como, por exemplo, nos Ministérios de Educação (CAPES) e Ciência, Tecnologia e Inovação (CNPq).
Nessas mais de quatro décadas de atuação, o Pós-Graduação em Letras formou 986 mestres e 426 doutores, até o momento, e foi o primeiro Programa de Pós-Graduação da PUCRS e do RS a atingir o nível de excelência internacional na Avaliação da CAPES (Conceito 6 na Trienal de 2004-2006), Inovou e foi novamente referência nacional ao criar, em 2011, a área de Escrita Criativa, tendo à frente dessa iniciativa o escritor e Prof. Dr. Luiz Antonio de Assis Brasil.

Cada um dos mais de 1.400 egressos dos cursos de mestrados e doutorado, cada um dos docentes e pesquisadores, cada um dos técnicos administrativos e cada um dos gestores que participaram desta trajetória merecem nosso reconhecimento e admiração. Que o futuro continue a propiciar, ancorado nas realizações do passado, ambiente e condições para o florescimento de inovações e avanços para a área de Letras de nosso país, seja na Linguística, na Teoria da Literatura ou na Escrita Criativa.

Recebido: 20 de setembro de 2015

Aprovado: 15 de outubro de 2015

Contato: audy@pucrs.br bellarm@pucrs.br 